\title{
Contexto de desenvolvimento e a percepção espacial de crianças
}

\author{
Ruy Jornada Krebs* \\ Joana Desiree Carniel ${ }^{* *}$
}

Zênite Machado****

\begin{abstract}
Resumo: Mudanças na estrutura social dos contextos onde a criança participa podem influenciar o desenvolvimento da percepção espacial. O objetivo deste estudo foi investigar os contextos de desenvolvimento e a percepção espacial de crianças, fundamentado na Teoria Bioecológica de Bronfenbrenner. O questionário de Machado (2008) foi utilizado com 60 crianças. Os resultados mostraram que a preferência pelo local de lazer está relacionada com a estrutura física, segurança, falta de autonomia das crianças, transporte e lugares frequentados pelos pais. Verificou-se que a percepção espacial das crianças está relacionada aos locais frequentados por elas como, a casa, a escola e o próprio bairro.
\end{abstract}

Palavras chave: Criança. Percepção espacial. Atividades de lazer.

\section{INTRODUÇÃO}

As mudanças sócio-urbanas ocorridas nas últimas décadas em resposta ao desenvolvimento industrial e consequente fluxo migratório campo cidade, alteraram significativamente a estrutura do grupo familiar e a rotina das crianças. O aumento da violência urbana, da densidade de veículos e da falta de espaços apropriados disponíveis ao lazer infantil nos grandes centros urbanos, influenciou na autonomia e na mobilidade das crianças. O estímulo espontâneo,

* Professor PhD da UDESC, responsável pelo Laboratório de Desenvolvimento e Aprendizagem Motora- Universidade do Estado de Santa Catarina. Florianópolis, SC, Brasil.

E-mail: d2rjk@hermes.udesc.br

** Professora de Educação Física, pesquisadora do Laboratório de Desenvolvimento e Aprendizagem Motora da Universidade do Estado de Santa Catarina.Florianópolis, SC, Brasil E-mail: joanacarniel@hotmail.com

*** Professora Dra. da Udesc e orientadora no aboratório de Desenvolvimento e Aprendizagem Motora- Universidade do Estado de Santa Catarina. Florianópolis, SC, Brasil.

E-mail: d2zm@hermes.udesc.br 
as brincadeiras na rua com os colegas, a imprevisibilidade da aventura, do risco, do confronto com o ambiente natural, deram lugar ao estímulo residencial ou institucionalizado. Sem a imunidade que lhe é conferida pelo brincar espontâneo e pela relação com o ambiente em que se vive, a criança revela menor capacidade de defesa, adaptabilidade e autonomia para interagir com as novas experiências oferecidas pelo ambiente (SANTOS, M., 2000; FERREIRA NETO, 1997; OLIVEIRA, 2004).

A falta de área livre disponível e apropriada para a criança brincar durante o período de lazer contribuiu para a formação de uma rotina de vida baseada em atividades de baixo envolvimento físico, como brincar de jogos eletrônicos, e desenvolver atividades intelectuais, como deveres de casa, cursos de idiomas e informática (MACHADO, 2008). O sedentarismo, característica própria destes tipos de atividades, aliado ao alto consumo de alimentos industrializados, constitui uma das causas do aumento da taxa de obesidade infantil. Segundo dados da Organização Mundial de Saúde, 30,3\% das crianças de 6 a 11 anos têm excesso de peso e 15,3\% delas são obesas. A obesidade e o sedentarismo estão atrelado ao aumento da incidência de doenças cardiovasculares e diabetes, porém durante a infância além de causar danos à saúde, estes hábitos não saudáveis poderão influenciar de forma negativa no desenvolvimento motor (DARONCO; ETCHEPARE; RECH, 2005; ABESO, 2009).

O desenvolvimento motor depende da interação entre a criança (características do sujeito, como: peso, altura, qualidades físicas e psicológicas), o ambiente (condições do ambiente que cercam o sujeito, que são externos a ele e a tarefa, mas influencia em seu desempenho, como o tipo de piso, o espaço disponível) e a tarefa (estratégias e táticas individuais para alcançar o objetivo da tarefa) (NEWELL, 1986). Um ambiente inadequado ou pouco estimulante pode contribuir de forma negativa no desenvolvimento motor infantil (ABBOTT; BARTLETT, 2000; GABBARD; CAÇOLA, RODRIGUES, 2008; FERREIRA NETO, 2007; MACHADO, 2008).

É a partir das experiências motoras e exploração do meio em que se vive que se constrói a percepção espacial durante a infância.

Movimento, Porto Alegre, v. 17, n. 01, p. 195-211, janeiro/março de 2011. 
Através dela torna-se possível conhecer o ambiente onde se vive e a forma como se relaciona com o seu corpo, com os objetos ou com as pessoas através de suas ações motoras (GALLAHUE; OZMUN, 2005; HAYWOOD, GETCHELL, 2004). A elaboração da percepção espacial ocorre durante o desenvolvimento sensório motor, sendo lapidada por um processo sequenciado que evolui gradativamente acompanhando o desenvolvimento mental da criança até alcançar o período das operações concretas, quando torna- se capaz de desempenhar grande parte das habilidades perceptivo-motoras (PIAGET; INHELDER, 1978).

As interações genéticas e ambientais influenciam nesse processo fazendo com que as crianças se desenvolvam em ritmos e intensidades diferentes. Tornar o ambiente familiar, escolar e urbano estimulante pode contribuir positivamente para o desenvolvimento das crianças, uma vez que, ao descobrirem novos estímulos presentes no ambiente no qual elas estão inseridas, as possibilidades de interagir com o meio se multiplicam (BRONFENBRENNER, 2005; GALLAHUE; OZMUN, 2005; HAYWOOD; GETCHELL, 2004).

A identificação dos espaços de preferência das crianças, dos espaços mais utilizados por elas e dos constrangimentos urbanos negativos encontrados em grandes centros urbanos que influenciam na escolha das atividades desenvolvidas durante o dia e consequentemente no desenvolvimento da percepção espacial das crianças são dados que poderão auxiliar a comunidade científica, o grupo familiar e o poder público a rever, organizar ou criar novos espaços de lazer. Neste sentido, o objetivo deste estudo foi investigar a percepção do espaço urbano de crianças do município de Florianópolis-SC.

\section{Procedimentos METOdológICOS E DELIMITAÇÃO dO CONTEXTO dO ESTUDO}

O estudo baseado no modelo Bioecológico de Bronfenbrenner justifica-se pelo potencial que a teoria tem para explicar a indissociabilidade entre a pessoa em desenvolvimento e os contextos em que ela se insere. O modelo Bioecológico contempla a complexa

Movimento, Porto Alegre, v. 17, n. 01, p. 195-211, janeiro/março de 2011. 
interação entre o processo (a reciprocidade bidimensional entre pessoa e o contexto), a pessoa (cujo desenvolvimento é constante), o contexto (simbolizado por um conjunto de sistemas aninhados, desde a área mais interna que denominou de Microssistema, passando pelo meso- e exossistema, até a área mais externa denominada de Macrossistema) e o tempo (BRONFENBRENNER, 1996).

O Microssistema, considerado por Bronfenbrenner (1992) um padrão de atividades, papéis e relações interpessoais experienciados pela pessoa em desenvolvimento, está relacionado ao ambiente mais imediato da criança, que neste estudo será representado como a casa e a escola. O mesossistema inclui as inter-relações entre dois ou mais ambientes em que a criança participa ativamente, como, por exemplo, a rede social que se estabelece entre a família e a escola. Já o exossistema, se refere a um ou mais ambientes que não envolvem a pessoa em desenvolvimento como um participante ativo, mas no qual ocorrem eventos que afetam, ou são afetados, por aquilo que acontece no ambiente contendo a pessoa em desenvolvimento, como por exemplo, o ambiente de trabalho dos pais (BRONFENBRENNER, 1992). E por fim, o Macrossistema, que pode ser visto como a arquitetura social de uma cultura particular, subcultura ou outro contexto social maior (BRONFENBRENNER, 1992), ou seja, é o contexto mais abrangente do modelo, que neste estudo representaremos como sendo o município de Florianópolis em toda a sua abrangência sociodemográfica e cultural.

A escolha do município justifica-se por Florianópolis ser uma capital com boa qualidade de vida (em 2000 foi a quarta do ranking da ONU com melhor qualidade de vida do Brasil) que recebe um grande número de visitantes ao longo do ano e pelo aumento populacional decorrente da migração de pessoas que transferem seus domicílios em busca de qualidade de vida e oportunidade econômica (a cada ano o município ganha em média 10 mil novos moradores, e sua população de 408.161 habitantes chega a dobrar durante o verão) (IBGE, 2010). Como consequência dessa transferência, a cidade tem sofrido com problemas de trânsito, pobreza, ocupação de área irregular e violência. Para a análise do contexto escolar, foi escolhida a maior escola do estado que está situada na zona central

Movimento, Porto Alegre, v. 17, n. 01, p. 195-211, janeiro/março de 2011. 
de Florianópolis. Essa escola congrega crianças residentes em diferentes regiões da cidade e de diferentes estratos sociais.

\subsection{Participantes do estudo}

Fizeram parte do estudo 60 crianças matriculadas na primeira série da referida escola, com idade entre 6 e 7 anos, que foram selecionados de maneira intencional. O termo de consentimento livre e esclarecido foi obtido para cada participante do estudo e o projeto foi aprovado pelo Comitê de Ética Pesquisa em Seres Humanos CEFID-UDESC sob o protocolo de número 9503/08.

\subsection{PROCEDIMENTOS PARA A COLETA DOS DADOS E INSTRUMENTOS UTILIZADOS}

Para as coletas dos dados utilizou-se o Questionário de Conhecimento Espacial, Apreciação e Representação do Espaço Urbano (QCEAREU) de Machado (2008), composto por questões que consideram os diferentes ambientes físicos como: a cidade, a casa onde mora, o bairro, a escola e seus arredores.

A fim de que os participantes retratassem com detalhes os locais mais frequentados e atraentes e, os locais e episódios não agradáveis da cidade, o objetivo do estudo foi explicado às crianças e solicitado que as mesmas, nas duas semanas que antecederam a coleta de dados, observassem com atenção todos os caminhos que elas percorressem em Florianópolis. Os dados foram coletados em forma de entrevista individual na referida escola durante o período de 5 dias, porém cada criança respondeu apenas uma vez o questionário. Cada participante respondeu as questões de acordo com as observações realizadas durante a semana anterior às coletas e levando-se em conta a percepção que possuem do ambiente em que vivem. O tempo de cada coleta foi de aproximadamente 15 minutos para cada criança.

\subsection{ANÁLISE ESTATíSTICA DOS RESULTADOS}

Os dados foram analisados de forma descritiva (frequência e tabelas de contingência), visto que o objetivo do estudo foi descrever o contexto da cidade em relação à percepção das crianças quanto a gostar ou não da cidade em que vivem, aos locais existentes na

Movimento, Porto Alegre, v. 17, n. 01, p. 195-211, janeiro/março de 2011. 
cidade e no bairro e aos espaços da escola e da casa. O teste de associação de variáveis qualitativas, Qui-quadrado, foi utilizado para analisar as variáveis de: facilidade de deslocamento associada ao meio de locomoção; locais de preferência para o lazer associada ao meio de locomoção descritos no item da Percepção Espacial no Macrossistema.

\section{ANÁLISE dOS RESULTADOS E DISCUSSÕES}

\subsection{PercepÇÃo espacial No MACROSSISTEMA}

Inicialmente serão apresentados os resultados referentes ao Macrossistema onde estarão incluídos os dados relacionados à estrutura física do município. A tabela 1 apresenta os dados referentes a relação afetiva da criança com o ambiente.

Tabela 1 - Relação afetiva da criança com o Macrossistema

\begin{tabular}{|c|c|c|c|c|c|c|c|}
\hline \multicolumn{2}{|c|}{$\begin{array}{l}\text { Você gosta de viver } \\
\text { em Florianópolis? }\end{array}$} & \multicolumn{6}{|c|}{ Quais os motivos? } \\
\hline Sim & Não & Natureza & $\begin{array}{l}\text { Locais } \\
\text { divertidos }\end{array}$ & Praias & $\begin{array}{l}\text { Locais para } \\
\text { brincar }\end{array}$ & $\begin{array}{l}\text { Pela } \\
\text { Beleza }\end{array}$ & Total \\
\hline $100 \%$ & $0 \%$ & $40 \%$ & $33,3 \%$ & $10 \%$ & $10 \%$ & $6,7 \%$ & $100 \%$ \\
\hline \multicolumn{2}{|c|}{$\begin{array}{c}\text { Florianópolis } \\
\text { é uma cidade } \\
\text { bonita? }\end{array}$} & \multicolumn{6}{|c|}{ Quais os motivos? } \\
\hline Sim & Não & Natureza & Agradável & Praias & $\begin{array}{l}\text { Locais para } \\
\text { brincar }\end{array}$ & Flora & Total \\
\hline $100 \%$ & $0 \%$ & $56,8 \%$ & $13,3 \%$ & $13,3 \%$ & $13,3 \%$ & $3,3 \%$ & $100 \%$ \\
\hline \multicolumn{8}{|c|}{ Quais locais ou objetos da cidade te fazem lembrar Florianópolis? } \\
\hline \multicolumn{2}{|c|}{ Ponte Hercílio Luz } & $\begin{array}{l}\text { Parques } \\
\text { e praças }\end{array}$ & Escola & $\begin{array}{l}\text { Mercado } \\
\text { público }\end{array}$ & $\begin{array}{l}\text { Shopping } \\
\text { Beira Mar }\end{array}$ & Carros & Total \\
\hline \multicolumn{2}{|c|}{$30 \%$} & $26,7 \%$ & $23,3 \%$ & $13,3 \%$ & $3,3 \%$ & $3,3 \%$ & $100 \%$ \\
\hline
\end{tabular}

Todas as crianças responderam que gostam de viver em Florianópolis, e o principal motivo relacionado a esta escolha é devido

Mavimento, Porto Alegre, v. 17, n. 01, p. 195-211, janeiro/março de 2011. 
à natureza existente no município (40\%). A atratividade do local, segundo elas, está relacionada à natureza $(56,80 \%)$, e com relação às lembranças e o símbolo do município, a Ponte Hercílio Luz, conhecida como o cartão postal de Florianópolis, é o local de preferência (30\%). Nessa perspectiva Haywood e Getchell (2004) enfatizam que a percepção espacial tem relação com a capacidade do ser humano de perceber o ambiente e a forma como se relaciona nele com seu corpo, com os objetos ou com outras pessoas através de suas ações motoras. Os resultados deste estudo demonstram a reciprocidade das crianças com o ambiente, representada pela relação afetiva delas com os símbolos e estrutura urbana do município, uma vez que descrevem os gostos, as preferências e as lembranças, da maneira como percebem o ambiente. Esta reciprocidade, segundo Bronfenbrenner e Morris (1999), é de fundamental importância visto que, principalmente nas fases iniciais do ciclo vital, o desenvolvimento da criança ocorre por meio de processos progressivamente mais complexos de interações recíprocas entre a criança em desenvolvimento e as pessoas, objetos e símbolos no ambiente externo imediato. Dessa forma, essa interação bidimensional entre a criança e o ambiente influencia positivamente o desenvolvimento infantil (BRONFENBRENNER, 1992; BRONFENBRENNER, 2005).

As estruturas físicas do Macrossistema podem influenciar nas preferências pelos locais e consequentemente na realização das atividades. A tabela 2 apresenta os resultados referentes à avaliação da estrutura física do Macrossistema.

Tabela 2 - Avaliação da estrutura física do Macrossistema

\begin{tabular}{cccccc}
\hline \multicolumn{2}{c|}{$\begin{array}{c}\text { É Bom viver em } \\
\text { Florianópolis? }\end{array}$} & \multicolumn{4}{c}{ Quais os motivos? } \\
\hline Sim & Não & $\begin{array}{c}\text { Opções de } \\
\text { Lazer }\end{array}$ & Parques & $\begin{array}{c}\text { Natureza } \\
\text { preservada }\end{array}$ & Total \\
$100 \%$ & $0 \%$ & $50 \%$ & $36,7 \%$ & $13 \%$ & $100 \%$ \\
\hline \hline \multicolumn{6}{l}{ Quais são os melhores locais de Florianópolis para frequentar durante o lazer? } \\
\hline Shopping & Escola & Praias & Cinema & Parques & Total \\
$40 \%$ & $23,3 \%$ & $20 \%$ & $12,2 \%$ & $4,5 \%$ & $100 \%$ \\
\hline \hline
\end{tabular}

Movimento, Porto Alegre, v. 17, n. 01, p. 195-211, janeiro/março de 2011. 
(continuação)

\begin{tabular}{cccccc}
\hline \hline \multicolumn{6}{c}{ Quais são as piores coisas de Florianópolis que influenciam na escolha do local } \\
de lazer?
\end{tabular}

De acordo com os dados apresentados na tabela 02 , observa-se que todas as crianças consideram este Macrossistema um lugar bom para viver principalmente pelas opções de lazer (50\%). Embora Florianópolis tenha 42 praias catalogadas, apenas $20 \%$ das crianças preferem frequentá-las. A maior parte delas (40\%) prefere os shoppings e a escola $(23,3 \%)$ também destacada como um local de lazer.

Esta escolha pode estar atrelada a questões de segurança, e ao nível da qualidade e quantidade de parques infantis existentes no município, pois, observou-se que $50 \%$ das crianças, relatam a violência como a pior coisa deste contexto e $16,7 \%$ delas consideram a falta de parques como a segunda pior coisa da cidade. Com relação a violência, pode-se crer que nesta fase da vida a maioria das crianças, provavelmente, não tenha uma concepção definida sobre o significado de violência. $\mathrm{O}$ fato de relatarem como a pior coisa da cidade pode ser reflexo da força do exossistema, ou seja, apesar das crianças não participem ativamente dos contextos nos quais os adultos estão envolvidos, elas são influenciadas indiretamente pelos comportamentos de adultos de outros contextos. A interpretação que as crianças fazem dos espaços disponíveis ao lazer pode estar relacionada também, ao tempo de permanência nas instituições escolares, idas frequentes aos shoppings com familiares e pela estrutura e segurança que estes locais oferecem a toda a família, refletindo mais uma vez as influências dos exossistemas nas escolhas da criança. A criança dependente da cultura familiar e social molda suas experiências de acordo com as vivências diárias, sendo que os hábitos de vida dos pais, a estrutura social, a cultura e estrutura urbana, influenciam diretamente nos hábitos de vida delas e até mesmo em sua vida futura (BRONFENBRENNER, 2005). Assim, contextos que oportunizem essa maior interação entre indivíduo e ambiente tendem a favorecer e propiciar disposições gerativas que impulsionam o desenvolvimento motor da criança.

Movimento, Porto Alegre, v. 17, n. 01, p. 195-211, janeiro/março de 2011. 
Este estudo vai ao encontro ao de Machado (2008), realizado com crianças de 8 a 12 anos no mesmo Macrossistema e contexto escolar. Isso demonstra que as crianças de 6 a 12 anos pertencentes a este Macrossistema tem percepções muito similares, ou seja, embora cada criança pertença a um Microssistema distinto, as forças dos exossistemas e a arquitetura social deste Macrossistema podem estar sendo refletidas nas percepções das crianças. O período cronológico deve ser levado em consideração, segundo Bronfenbrenner (1979), quando se investiga um fenômeno, entretanto, embora o período cronológico do estudo de Machado (2008) tenha sido diferente desse estudo, pode-se observar que o Macrossistema não sofreu grandes modificações em termos de estruturação urbana, lazer e segurança, visto a convergência das percepções das crianças em ambos os estudos.

A tabela 3, apresenta os resultados referentes a maneira como as crianças percebem a cidade em que vivem e de que maneira gostariam que ela fosse.

Tabela 3 - Comparação da avaliação realizada pela criança de como é e como deseja que Florianópolis fosse.

\begin{tabular}{cc|cc}
\hline \multicolumn{2}{c|}{ Florianópolis é: } & Gostaria que Florianópolis fosse: \\
\hline Agradável & $100 \%$ & Agradável & $100 \%$ \\
Barulhenta & $53 \%$ & Barulhenta & $27 \%$ \\
Maior & $100 \%$ & Maior & $80 \%$ \\
Complexa & $100 \%$ & Complexa & $100 \%$ \\
Atrativa & $100 \%$ & Atrativa & $100 \%$ \\
Povoada & $100 \%$ & Povoada & $80 \%$ \\
Imensa & $100 \%$ & Imensa & $100 \%$ \\
Segura & $57 \%$ & Segura & $100 \%$ \\
Confortável & $100 \%$ & Confortável & $100 \%$ \\
Alegre & $100 \%$ & Alegre & $100 \%$ \\
Forte & $100 \%$ & Forte & $100 \%$ \\
Clara & $100 \%$ & Clara & $100 \%$ \\
Acolhedora & $100 \%$ & Acolhedora & $100 \%$ \\
Agitada & $100 \%$ & Agitada & $80 \%$ \\
Grandiosa & $100 \%$ & Grandiosa & $100 \%$ \\
Tranqüila & $100 \%$ & Tranqüila & $100 \%$ \\
\hline
\end{tabular}

De acordo com os dados apresentados na tabela 3, pode-se dizer que este Macrossistema apesar das dificuldades de organização

Movimento, Porto Alegre, v. 17, n. 01, p. 195-211, janeiro/março de 2011. 
urbana, apresenta no geral um bom ambiente de vida para seus moradores na percepção das crianças. De acordo com o último Índice de Desenvolvimento Humano municipal (IDH-m) calculado no ano de 2000, este Macrossistema foi considerado pela ONU (Organizações das Nações Unidas), como a capital brasileira com melhor IDH-m do país e a quarta cidade com melhor qualidade de vida do Brasil (IBGE, 2010). Os resultados do presente estudo estão de acordo com os obtidos por de Machado (2008), no qual as crianças julgaram o Macrossistema como um bom ambiente de vida. Porém, a necessidade de planejamento urbano já havia sido citado no estudo de Boeira (2004) que destacou a necessidade de um planejamento urbano que atendesse as limitações biofísicas (áreas de preservação), as pressões populacionais aceleradas pelo turismo massivo (produção de lixo, trânsito), especulação imobiliária, violência urbana, tráfico de drogas, marginalização social, para evitar uma crise urbana futura.

Estudos nacionais e internacionais buscam compreender como a independência de mobilidade (capacidade de autonomia, ou seja, a possibilidade de tomar decisão por si própria) tem sido um fator crucial no desenvolvimento motor da criança (MACHADO, 2008; FERREIRA NETO, 2007). Nesse estudo, ao relacionar a facilidade de deslocamento (relatado pela criança) e meio de locomoção utilizados pelas crianças $(p<0,01)$, verificou-se a preferência em utilizar automóvel o que, provavelmente, ocorra em decorrência da dificuldade de deslocamento nesse Macrossistema, uma vez que apenas $20 \%$ das crianças vão a pé para a escola.

Fatores como a densidade de veículos transitando pelas ruas, a violência urbana, a falta de vias destinadas aos pedestres ou ciclistas e, principalmente, a falta de autonomia delegada às crianças podem, também, estar influenciando na escolha das crianças. O caminhar ou pedalar enriquece e estimula a criança a estruturar um plano de rota imaginário de partida e chegada, de tempo de percurso e de possíveis obstáculos presentes no caminho e é a partir da organização simbólica de estruturas reconhecíveis (delimitação de ruas, edifícios, jardim, a casa do amigo) que se organiza uma estrutura simbólica do ambiente coerente (FERREIRA NETO, 2007; PIAGET; INHELDER, 1978). A capacidade de a pessoa desenvolver imagens

Movimento, Porto Alegre, v. 17, n. 01, p. 195-211, janeiro/março de 2011. 
mentais dos lugares está relacionada à maneira com que ela percebe o ambiente e principalmente na relação produzida por esta vivência. A falta do hábito de se locomover a pé pode estar influenciando o aumento progressivo do sedentarismo infantil, o qual é proporcional à diminuição da qualidade do contexto em termos de condições ambientais e oportunidades de prática (FERREIRA NETO, 2007).

$\mathrm{Na}$ análise entre o meio de locomoção associado aos espaços de lazer que preferem frequentar, $51,6 \%$ das crianças que optaram pelo transporte automotivo (particular ou coletivo) preferem ir aos shoppings $(\mathrm{p}<0,01)$ e apenas $18,3 \%$ preferem ir às praias $(\mathrm{p}<0,03)$. Analisando as crianças que preferem andar a pé $(11,6 \%)$ nota-se que estas também dão preferência aos shoppings $(\mathrm{p}<0,01)$. Estes dados demonstram que os meios de locomoção disponíveis às crianças e a infra-estrutura urbana, influenciam no desenvolvimento infantil, uma vez que os locais de preferência para o lazer estão relacionados ao acesso limitado do transporte viário (transporte coletivo) e 63,3\% dos participantes do estudo optam pelo shopping como o espaço de lazer de preferência. A preferência das crianças pelos shoppings como local de lazer, pode ter relação com a segurança e a facilidade de acesso, uma vez que esses estão localizados em áreas de grande movimentação populacional, onde o transporte coletivo é mais frequente e as vias de acesso estão em melhores condições.

Nessa perspectiva, as crianças foram questionadas quanto aos locais existentes nos bairros em que residem de acordo com categorias pré-estabelecidas pelo questionário de Machado (2008) (Tabela 4).

Tabela 4 - Espaços existentes no bairro em que vivem

\begin{tabular}{ccc}
\hline $\begin{array}{c}\text { O bairro que você vive } \\
\text { possui: }\end{array}$ & Sim & Não \\
\hline Espaços verdes & $33,3 \%$ & $66,7 \%$ \\
Espaços de aventura & $3,3 \%$ & $96,7 \%$ \\
Espaços multi-esportivo & $63,3 \%$ & $36,7 \%$ \\
Espaços livres e abertos & $6,7 \%$ & $93,3 \%$ \\
Jardins públicos & $70 \%$ & $30 \%$ \\
Parques infantis & $46,7 \%$ & $53,3 \%$ \\
Museus & $0 \%$ & $100 \%$ \\
Cinemas & $6,7 \%$ & $93,3 \%$ \\
& & (continua...)
\end{tabular}

Movimento, Porto Alegre, v. 17, n. 01, p. 195-211, janeiro/março de 2011. 
206 Astigor Originais

(continuação)

Igrejas

Shoppings

Teatros
Ruy Jornada Krebs et al.

$33,3 \%$

$80 \%$

$96,7 \%$

Os espaços de maior frequência nos bairros foram os jardins públicos (70\%), as igrejas $(66,70 \%)$ e os espaços multi-esportivos $(63,30 \%)$. Para conhecer as oportunidades que os bairros e o município oferecem, é necessário que a criança transite com segurança e autonomia pelo local onde vive. Para muitas delas, o caminho de casa até a escola é o limite da percepção que possuem da cidade (SERRANO; 1996; LOPES; COELHO, 2003). Nessa fase da vida é comum que as crianças frequentem os locais de preferência dos pais devido à falta de autonomia em decorrência dos cuidados e da proteção que necessitam nessa idade. Porém, é necessário que os pais conheçam as necessidades das crianças e principalmente que invistam em frequentar locais onde a cultura e o brincar sejam estimulados, como os passeios aos museus, teatros, parques, praças. A escola, como extensão da casa familiar poderá auxiliar neste processo, incluindo em seus temas transversais passeios e atividades que estimulem a frequência nesses locais.

\subsection{PeRCEPÇÃo ESPACIAL NO MICROSSISTEMA}

Serão apresentados os resultados referentes ao Microssistema com dados relacionados à estrutura física dos contextos familiar e escolar. As crianças foram questionadas com relação aos aspectos existentes na rua, na casa e na escola (Tabela 5). Tabela 5 - Aspectos existentes na rua, na casa e na escola

Movimento, Porto Alegre, v. 17, n. 01, p. 195-211, janeiro/março de 2011. 
Tabela 5 - Aspectos existentes na rua, na casa e na escola

\begin{tabular}{cccccc}
\hline $\begin{array}{c}\text { O que } \\
\text { lembra a rua } \\
\text { onde mora }\end{array}$ & Frequência & $\begin{array}{c}\text { O que } \\
\text { lembra a } \\
\text { casa onde } \\
\text { mora }\end{array}$ & Frequência & $\begin{array}{c}\text { O que } \\
\text { lembra a } \\
\text { escola onde } \\
\text { estuda }\end{array}$ & Frequência \\
\hline $\begin{array}{c}\text { Vizinhos } \\
\text { Amigos }\end{array}$ & $34,99 \%$ & Família & $36,67 \%$ & Pátio & $36,66 \%$ \\
$\begin{array}{c}\text { Venda/ mer- } \\
\text { cado }\end{array}$ & $26,66 \%$ & Brinquedos & $33,33 \%$ & Parquinho & $30 \%$ \\
$\begin{array}{c}\text { Cachorros } \\
\text { Total }\end{array}$ & $8,35 \%$ & O quarto & $30 \%$ & Recreio & $18,34 \%$ \\
Total & & & $\begin{array}{c}\text { Aulas de } \\
\text { Educação } \\
\text { Física }\end{array}$ & $15 \%$ \\
\hline
\end{tabular}

Os resultados apresentados na Tabela 5, demonstram que as crianças entrevistadas têm fortes relações interpessoais, fundamental para a qualidade de um Microssistema, sendo que $71,65 \%$ das lembranças delas remetem à interações sociais. Bronfenbrenner enfatiza em seus estudos que os laços afetivos das crianças com os vizinhos e amigos são considerados aspectos que contribuem para a formação dos processos proximais e para o desenvolvimento da criança (BRONFENBRENNER, 2005).

Com relação ao ambiente doméstico, as maiores lembranças foram a família $(36,67 \%)$, os brinquedos $(33,33 \%)$ e o quarto $(30 \%)$. É do ambiente familiar que partem os valores, os costumes, os credos e as primeiras relações interpessoais que de um modo geral, determinarão através das diferentes gerações as características dos contextos em que as crianças estão inseridas. A forma como as famílias reagem a uma transição histórica ou a uma mudança de papel afeta o curso de desenvolvimento de outros membros da família, principalmente das crianças, considerando que nesta fase elas são dependentes da cultura familiar (BRONFENBRENNER; MORRIS, 1998). Os resultados demonstram também que a criança passa boa parte do seu tempo dentro de casa brincando, visto que elas mencionaram os brinquedos e o quarto como fatores que mais lembram a própria casa. Sendo assim, esses Microssistemas têm contribuído para um melhor desenvolvimento dessas crianças, visto que o ato de brincar propicia a criança uma melhor exploração do meio.

Movimento, Porto Alegre, v. 17, n. 01, p. 195-211, janeiro/março de 2011. 
Com relação às lembranças do ambiente escolar, todas as citações foram relacionadas ao envolvimento físico e a prática de brincadeiras ou esportes, como o pátio (36,66\%), parquinho (30\%), recreio $(18,34 \%)$ e as aulas de Educação Física (15\%). Entretanto as crianças relataram com maior frequência $(85 \%)$ os momentos em que brincam espontaneamente. Ferreira Neto (1997) relata que a gestão de tempo escolar e o tempo adicional passado em atividades organizadas ou institucionalizadas, não permitem às crianças o uso do tempo considerado verdadeiramente livre (espontâneo), consequência provável das transformações urbanas e da construção de imaginários de segurança que os pais têm na educação dos filhos. Considerando-se os espaços disponibilizados às crianças para as brincadeiras como um Microssistema, pode-se dizer que a atividade espontânea e prazerosa denominada jogo tem grande potencial para constituir-se em atividades molares (significativas), instigativas ao desenvolvimento da criança. Embora as aulas de educação física também tenham sido citadas $(15 \%)$, essa menor porcentagem pode estar atrelada à significância das tarefas motoras propostas ou aos achados de Santos (2008), que relatou que a indisciplina das crianças, a resistência a novos conteúdos e a falta de interesse/motivação por parte das crianças, podem estar relacionada à significância da tarefa realizada.

\section{ConsideraçõEs FINAIS}

Para que a criança se desenvolva adequadamente, é necessário que o ambiente em que ela esteja inserida seja adequado as suas necessidades de movimentação. Neste estudo conclui-se que os espaços públicos destinados ao lazer infantil como parques e praças existentes na cidade não suprem as necessidades das crianças devido a estrutura física ou aspectos relacionados a falta de segurança. Entretanto, a preferência da criança por frequentar estes espaços também influencia neste processo. A rotina e a cultura familiar somada aos constrangimentos urbanos como a falta de tempo para exercer atividades de lazer e a falta de segurança nos centros urbanos, influenciam nas eleições e preferências das crianças.

Movimento, Porto Alegre, v. 17, n. 01, p. 195-211, janeiro/março de 2011. 
Conclui-se que o desenvolvimento da percepção espacial no ambiente urbano está diretamente relacionado com a mobilidade da criança, com os hábitos de vida dos familiares, com a qualidade das oportunidades motoras oferecidas pelos locais frequentados pelas crianças no cotidiano e pelas atividades desenvolvidas diariamente por elas independente do contexto.

Com relação as oportunidades motoras encontradas no Macrossistema, conclui-se que é necessário investir em políticas públicas que garantam a segurança no município, e dessa forma, investir em locais apropriados ao lazer infantil para a criança possa ter autonomia concedida pelos pais para explorar o ambiente em que está inserida durante o tempo livre e desenvolver-se adequadamente. Com relação ao Microssistema, conclui-se que é necessário estimular motoramente as crianças através de brincadeiras ativas e de preferência que elas ocorram em espaços abertos.

Em relação aos ambientes em que a criança participa ativamente e os hábitos de vida, pode-se concluir que as relações interpessoais entre vizinhos, amigos e familiares são as mais significativas e influenciam nas escolhas das preferências e nos hábitos de vida diários.

Movimento, Porto Alegre, v. 17, n. 01, p. 195-211, janeiro/março de 2011. 


\begin{abstract}
Environment of development and children's spatial perception

Abstract: Structural changes in social contexts where children participate may influence the development of spatial perception. The aim of this children's was to investigate the contexts of development and spatial perception of children's, based on the Bioecological theory of Bronfenbrenner. The questionnaire of Machado (2008) was applied in 60 students. The results showed the preference for leisure place is related to physical structure, security, lack of autonomy of children, transportation and places frequented by parents. The spatial perception of children is related to places frequented by them as home, school and the neighborhood.

Keyword: Children. Space Perception. Leisure activi-

ties.
\end{abstract}

Contexto del desarollo y la percepción del espacio
en los niños
Resumen: Los cambios estructurales en los contextos
sociales donde los niños participan pueden influenciar
en el desarrollo de la percepción espacial. El objetivo de
este estudio fue investigar los contextos del desarrollo
y la percepción espacial de los niños basados en la
teoria Bioecologica de Bronfenbrenner. El cuestionario
Machado (2008) fue utilizado con 60 estudiantes. Los
resultados mostraron que la preferencia por el ocio local
está relacionada con la estructura física, la seguridad,
la falta de autonomia de los niños, el transporte y los
sitios frecuentados por los padres. Se encontró que la
percepción espacial de los niños está relacionada con
los sitios frecuentados por ellos, como por ejemplo, la
casa, la escuela y el propio bario.
Palabras clave: Niños. Percepción Espacial. Activi-
dades recreativas

\title{
REFERÊNCIAS
}

ABESO. VIGITEL: o número da obesidade no Brasil, 2009. Disponível em <http:// www.abeso.org.br/pdf/Obesidade $\% 20$ no $\% 20$ Brasil\%20VIGITEL $\% 202009 \% 20$ POF2008_09\%20\%20II.pdf Acesso em 19 maio 2010.

ABBOTT, Andrew; BARTLETT, Doreen. J. Infant motor development and equipment use in the home. Child: Care, Health and Development, Oxford, v. 27, n. 3, p. 295- 306, 2000.

Movimento, Porto Alegre, v. 17, n. 01, p. 195-211, janeiro/março de 2011. 
BOEIRA, Sérgio Luís. Desenvolvimento urbano e crise de paradigmas: o caso da região de Florianópolis. Percursos, Florianópolis, v. 6, n. 2, p. 1-28, 2005.

BRONFENBRENNER, Urie. The ecology of human development: experiments by nature and design. Cambridge, Massachusetts: Harvard University, 1979.

Making Human Being Human: biecological perspectives on human development. Thousand Oaks: SAGE, 2005.

Ecological System Theory. In: ROSS, Vasta. Six Theories of Child Development: revised formulations and current issues. London: Jessica Knigsley, 1992. p. 187-249.

BRONFENBRENNER, Urie; MORRIS, Pamela. The ecology of developmental processes. In: DAMON, William.; LERNER, Richard. M. (Org.). Handbook of child psychology. New York: John Wiley, 1998. v. 1: Theoretical models of human development. p. 993-1028.

The Ecology of Developmental Process. In: PEDRO, João Gomes (Ed) Stress and Violence in Childhood and Youth. Lisboa: Faculdade de Medicina, Universidade de Lisboa, 1999. p. 21-95.

DARONCO, Anderson; ETCHEPARE, Luciane; RECH, Cassiano. O estudo de massa corporal e desempenho motor de escolares de Santa Maria. Lecturas Educación Fisica y Deportes, Buenos Aires, v.10, n. 89, 2009.

FERREIRA NETO, Carlos Alberto. O jogo e o cotidiano de vida da criança. In: KREBS, Ruy Jornada; FERREIRA NETO, Carlos Alberto. Tópicos em desenvolvimento motor na infância e adolescência. Rio de Janeiro: Nova Letra, 2007.p. 122- 135.

Tempo e espaço de jogo para a criança: rotinas e mudanças sociais. In. FERREIRA NETO, Carlos Alberto (Ed.). O jogo e o desenvolvimento da criança. Lisboa: Edições FMH, 1997. p. 10-22.

FROST, Joe. Play and playscapes. New York: Delmar, 1992.

GABBARD Carl; CAÇOLA, Priscila; RODRIGUES Luis Paulo. A New Inventory for Assessing Affordances in the Home Environment for Motor Development (AHEMDSR). Early Childhood Educ., Edmonton, CA, n. 36, p. 5-9, 2005.

GALLAHUE, David; OZMUN, John. Compreendendo o desenvolvimento motor: bebês, crianças, adolescentes e adultos. 3. ed. São Paulo: Phorte, 2005.

HAYWOOD, Kathleen ; GETCHELL, Nancy. Desenvolvimento motor ao longo da vida. 4. ed. Porto Alegre: Artmed, 2004.

IBGE. Área Territorial: Resolução 05, de 10 de outubro de 2002. Disponível em <http://www.ibge.gov.br/home/geociencias/areaterritorial/area.php.>Acesso em: 17 maio 2010. > Acesso em: 17 maio 2010.

KREBS, Ruy Jornada; FERREIRA NETO, Carlos Alberto. Tópicos em desenvolvimento motor na infância e na adolescência. Rio de Janeiro: Nova letra, 2007.

Movimento, Porto Alegre, v. 17, n. 01, p. 195-211, janeiro/março de 2011. 


\section{Antifor Originais}

LOPES, Maria Calado; COELHO, Edviges. Diferenças e semelhanças no uso do tempo das crianças e dos adultos em Portugal. Boletim da Sociedade Portuguesa de Educação Física, Lisboa, p. 9-31, jan/abr. 2003.

MACHADO, Zenite. A criança, a cidade e os espaços de jogo. Dissertação (Doutorado)- Curso de Educação Física, Universidade Técnica de Lisboa, Lisboa, 2008.

NEWELL, Karl. Constraints on the development of the coordination. In: WADE, M.G; WHITING, H. T. A. (Ed.). Motor Development in children: aspects of control and coordination. Dordrecht: Martinus Nyhof, 1986.

OLIVEIRA, Claudia. O ambiente urbano e a formação da criança. São Paulo: Aleph, 2004.

PIAGET, Jean; INHELDER, Bärbel. A psicologia da criança. São Paulo: Difel, 1978.

SANTOS, I. L. et al. As percepções e os significados para os estagiários de educação física em relação a indisciplina na escola. Movimento, Porto Alegre, v. 14, n. 3, p. 117-137, 2008.

SANTOS, Milton. Por uma outra globalização: do pensamento único à consciência universal. Rio de Janeiro: Record, 2000.

SERRANO, João. Envolvimento social e desenvolvimento da criança: estudo das rotinas de vida diária das crianças com idade compreendidas entre os 7 e os 10 anos nos meio rural e urbano. Dissertação (Mestrado em Motricidade Humana)Universidade Técnica de Lisboa, Lisboa, 1996.

VAN GILS, Jan. Leisure activities of children: with or without agenda. International Play Journal, London, v. 4, p. 133-143, 1996.

Movimento, Porto Alegre, v. 17, n. 01, p. 213-235, janeiro/março de 2011. 